\title{
Using Smartphones in Learning Arabic by AOU Students
}

\author{
Issa Khalil Alhasanat ${ }^{1}$ \\ ${ }^{1}$ Department of education, Arab Open University, Jordan \\ Correspondence: Issa Khalil AlHasanat, Assistant Professor, Department of education, Arab Open University, \\ Jordan.
}

Received: October 15, 2019

Accepted: November 27, 2019 Online Published: December 6, 2019

doi:10.5539/hes.v10n1p48

URL: https://doi.org/10.5539/hes.v10n1p48

\begin{abstract}
The present article explores the use of smartphones by Arab Open University (AOU) students in learning the Arabic Language. The sample consisted of 275 students of those taking Arabic for primary school teachers. A questionnaire was prepared by the researcher to specify relevant uses and was divided into 4 sections: types of students' devices, useful services, students' purposes of using such services and challenges to the learning of Arabic on these devices.

The results showed, first, that most students used smartphones, by different percentages, except for the GPS application. Second, they made use of all the services, by various percentages, except for those of games and image viewers. Third, they used smartphones for diverse purposes, but not for administrative data related to learning Arabic. Fourth, there were numerous challenges to the learning process on these devices.

Finally, recommendations were made to develop the use of smartphones in learning Arabic according to the above findings.
\end{abstract}

Keywords: smartphone services, learning Arabic, university students

\section{Introduction}

Distant learning has managed to achieve a great portion of learning, since all human beings enjoy the right to learn regardless of any factor. Learning and teaching took different forms in different stages through the computer, e-learning and then smartphones. Such devices have become available in every house and, almost, with every individual.

Due to their capabilities and the many services they provide to meet people's needs, smartphones have a great impact on societies. They assist several aspects like health, politics and economy. For instance, public health departments in South Africa send SMS to tuberculosis patients to remind them of medication times. In Kenya, people can send questions on health issues through free SMS and they receive quick replies by experts (Corbett, 2008).

Among the most relevant sectors is education. Students use smartphone services to pass examinations, improve skills, find new learning opportunities and be prepared for a bright future. As ICT creates new learning methods, smartphones have gradually occupied most educational fields in developing and developed countries alike, assisted by most students' good awareness of dealing with such devices.

Thus, according to Goh and Kinshuk (2006), learning through smartphones will constitute the next significant wave in learning environments, moving away from childhood to maturity. On the other hand, scholars are rushing to investigate the features of this use. They find that learning through smartphones can start from simple services, like SMS, to complicated ones, like videos, taking into consideration that the only steering study in this regard is Methods of Teaching.

Teachers and students try to use learning applications and seize chances to utilize any system which supports learning environments on these devices (Stanullu, 2008). A strength of this type of learning is that it may be used by everybody, as there are no differences of statistical significance in this regard between males and females or even between adults and children.

A smartphone is a mobile phone that can perform many tasks and computations like a personal computer. It is slowly replacing the old cell-phone, as it is equipped with a powerful operating system (multi-tasking) along with a myriad of useful applications (Apps) and high speed data communication capability. Hence, browsing the 
Internet or running Internet-based applications is intrinsic. A smartphone is a powerful handheld computer with an intrinsic connection mobile networks (Davies, 2015; Rouse, 2015; Anshari and Alas, 2015).

A smartphone is so handy and is becoming a multipurpose mobile device that can assist people to perform their daily as well as professional activities. Smartphones are used by many to access information and knowledge from the Internet. In fact, some people develop knowledge by accessing a pool of knowledge from the Internet using their smartphones. Hence, smartphones can definitely be taken as to enhance education (Almunawar et al., 2015). Nowadays, students can access information and knowledge easily from the Internet and they can also have discussions in social networks and get quick answers from peers, lecturers or even experts. Gerlich et al., (2010) found that many college students use smartphones to help them study.

The reliance on smartphones is quite evident and the usage of smartphones amongst youth and students is rapidly growing (Abeele, 2016). They spend a lot of time online and most of them prefer connection to the Internet using their smartphones instead of other devices (García-Ormaechea, 2014). Students normally bring their smartphones in classrooms and lectures. In fact, some students capture the lecture notes or other notes written or given by their lecturers using their smartphone cameras. Lecturers can even turn smartphones to become learning aids in class (Anshari et al., 2016). Some discussions or idea generations can be enhanced using a social network, which are accessible using smartphones, in a class to attract more participation from the students. However, smartphones at the same time can also create a serious disturbance during lectures if students play with their smartphones instead of paying attention to lectures (Anshari et al., 2015b).

Nowadays, both young and adults are dependent on smartphones (Course, 2011). Younger generation has grown up with electronics and technologies surrounding them and has significant exposure to these digital devices. However, many educators do not fully utilise smartphones' capabilities for learning. Smartphones with their many existing features and future potential uses can enhance learning but hardly replace classroom or conventional e-learning methods. Hence, learning with smartphones can only be used as a complementary to traditional learning and e-learning (Wang et al., 2009). As most current students are digitally literate they are referred to as digital natives, in contrasts with their teachers who are referred to as digital immigrants as most of them learn by adopting the digital world (Wang et al., 2009; Evans, 2009). In addition, smartphones in classrooms allow students to record video or audio, take pictures of teachers' explanations from the board or screen, and ask peers to share pertinent links to the class (Nakamura et al., 2015). Teachers can also allow students to read from their smartphones, share-interesting articles to others, and make silent e-group discussions. At the end of the sessions, teacher can ask them to present their silent learning in the classroom (Au et al., 2015).

Smartphone technology, with its pervasive acceptance and powerful functionality, would inevitably change peoples' behaviours and actions to keep up-to-date with it (Course, 2011; Anshari et al., 2015a). Some functionalities of smartphones are discovering that Apps for mobile devices most engaging ways to teach difficult subjects like math and science. For example, the free NASA App offers videos, images, and interactive displays that bring space to life in a way that a lecture never could (Katz, 2012). Research revealed that the use of digital devices in pervasive computing environment was capable of facilitating faculty-student interactions and in-class participations, which in turn enhanced engagement and active learning (Stephens, 2005). Digital devices had positive impacts on students' study habits and their academic success (Demb et al., 2004).

\subsection{Problem of the Study}

Learning the Arabic Language requires continuity. As what is learnt in class is not sufficient, relevant training is needed, along with life-long learning and interaction through different learning stages between all the educational process elements, namely: teachers, learners and curriculum. As people develop over time, new instruments are needed to boost interaction. In this age, smartphones, PDA's, mini-calculators and smartphones have spread like wildfire and entered almost every home. They provide many services which help Arabic Language learners in a better manner. They also support life-long learning, encourage interaction between the educational process elements and assist learning in any time and space. Mobile learning depends on using wireless technologies, which do not require specific places or times for the purpose of learning.

The present study is aimed at exploring the reality of the Arab Open University (AOU) students' use of smartphones in learning Arabic, besides the challenges they think hinder their learning through such devices.

The study attempts to answer the following questions:

1. What are the types of devices used by AOU students in learning Arabic?

2. What are the smartphone services used by AOU students in learning Arabic?

3. What are the purposes of AOU students when using smartphones in learning Arabic? 
4. What are the challenges AOU students think they encounter when using the learning services on their smartphones?

5. Are there any statistically significant differences related to the use of smartphones in learning Arabic attributed to age, sex or Academic average?

\subsection{Significance of the Study}

The significance of the study stems from the subject, as it provides valuable information to those interested and involved in teaching Arabic in a bid to enrich their teaching methods. Furthermore, the study looks into the vital issue of employing new technologies, especially smartphones, in learning Arabic and developing relevant services to assist the students' purpose. It also identifies the challenges thought by the learners to obstruct their use of such devices.

\subsection{Objectives of the Study}

The study is aimed at:

- Assessing the frequency of AOU's students' use of smartphones in learning Arabic

- Identifying the smartphone services used by AOU students in learning Arabic

- Identifying the AOU students' purposes of using smartphones in learning Arabic

- Identifying the challenges encountered by AOU students when using the smartphone learning services from their own perspective.

\subsection{Scope of the Study}

The present study is limited to:

- Academic year 2015-2016

- Sample from Amman-based AOU/Jordan students.

\subsection{Methodology of the Study}

The descriptive-analytical method is employed to specify to what extent AOU students use smartphones in learning Arabic. Descriptive studies relate and account for what is existent and are concerned with relevant conditions, relationships, processes and common views. Focus is laid on the results of the questionnaire to analyze the phenomenon and find answers to the questions of the study.

\subsection{Procedural Definitions}

The following terms are used in this study:

Learning through smartphones: employing any of the smartphone services in the learning process

Challenges to learning through smartphones: difficulties facing students when using smartphones in learning Arabic and, thus, reducing their use of relevant services

\subsection{Theoretical Framework}

There is no particular definition of learning through smartphones. It actually requires further explanation and specification, as it is a new learning method and in need for extensive investigation. This type of learning is believed to see a great deal of activity (Mohammad, 2009).

Many researchers consider learning through smartphones one type of e-learning (Quinn, 2000). Both are the same in terms of easy access to sources from anywhere, good search potential, rich interaction, strong support for interactive learning, performance-based assessment and online learning independently of time and space.

Some scholars concentrate on the devices used. For instance, it is defined by Traxler (2005) as learning supported by electronic tools and which employs mobile phones and other wireless connections.

There is a set of smartphone services which could be employed in the educational process. Among these are (Pernsky, 2005):

- Sound: It may be used for language lessons, dictionaries, hard book programmes, tourist brochures, tests, lectures through smartphones and easy feedback.

- SMS: They may be useful for quizzes, games, preparation and answer of tests, questionnaires, vivas, academic supervision, provision of more inclusive data and reactions.

- Data shows: They may be helpful for lectures, tests and cartoons. 
- Browsing the internet: It may provide basic internet tools and search engines.

- Downloadable applications: They can be used for cooperation tools, educational software, programming languages, connection with tools and other devices.

- Photography: It may help for data collection, documentation, news reports and innovative writing stimuli.

- Videos: They may be used for TV press and making of innovative movies.

- GPS: They may be helpful for field trips and multi-player search games.

- Exchange of e-books and e-files between learners: It may take place via Bluetooth or infrared, which cannot be found in other e-learning forms.

Several studies referred to the advantages gained by learners in learning through smartphones. For example, Sharples (2000) argued that learning through smartphones allowed students to learn wherever they are, even in their own contexts, which leads to meaningful learning.

Another analytical research (Atteiwell, 2005) looked into a number of studies on the results of learning through smartphones. Among the benefits found were assisting students to improve their reading, writing and number abilities; developing their cooperative learning experiences and independent learning; helping in identifying their requirements and provision of relevant support; assisting in overcoming inter-societal digital gap; supporting unofficial learning; helping learners for longer attention spans and promoting self-esteem and self-confidence.

Cavus and Dogan (2009) attempted to develop English vocabulary for freshmen at Jordanian universities through SMS. The target students enjoyed learning and acquired more new words than their peers did.

Shuler (2009) referred to the following advantages of learning through smartphones: promoting learning at any time and space; students' unlimited access to learning services with low connection costs; securing digital fairness, improving social interaction between learners; harmony with learning environments to overcome several technology-related challenges; natural reconciliation between different learning environments and introducing a personal aspect to the learning experiences.

Altakhneh (2018) conducted a study aimed at investigating the attitudes towards mobile learning in open learning systems of teaching mathematics, The sample of the study consisted of (57) male and female students enrolled in the mathematics course in the department of educational studies at the Arab Open University / Jordan branch for the academic year 2016/2017. Results of the study showed that the percentages of students' attitudes toward using mobile applications reached $80 \%$. Each of the following cores is ranked as ascending: mathematical thinking (75\%), achievement motivation (76\%), developing social and emotional skills 77\%, and application technology (96\%). There was no statistical significance difference $(\alpha \leq 0.01)$ between the variable type of general secondary certificate (scientific / literary stream) as well as the nature of work in terms of the fact that the learner is (employee / non-employee). In light of results of the study, the researcher recommends using mobile applications in teaching courses of mathematics in the open learning systems.

Imelda et.al (2019) conducted a study aims at investigating the effect of process writing approach combined with video-based mobile learning on the writing skill of Indonesian learners of English as a foreign language (EFL) across their creativity levels. A quasi experimental study was employed by involving 61 learners of Vocational High School learners in Indonesia. They were assigned into two groups: experimental and control. The treatment was conducted at 5 sessions, including the pre-test and post-test. The scores of pre-test and post-test in writing were used as a base of quantitative data analysis whereas the learners' responses to creativity questionnaire were used to categorize their creativity level. The result revealed that the process writing approach combined with video-based mobile learning was effective to enhance the learners' writing skill. Additionally, it was implied that to apply the combination of process writing approach and video-based mobile learning, teachers should not worry about the difference levels of the learners' creativity.

According to Shuler's report (2009), there are several objectives to be achieved by learning through smartphones, namely:

- Learning: Learning through smartphones can be an independent tool or element of the educational process. To this end, investment shall be carried out by realizing the core of development and introducing new special theories and forms. Current theories address traditional or e-learning. However, they do not investigate this type, bearing in mind that developing and some third world countries have moved directly from traditional learning to learning through smartphones without going through e-learning. 
- Development: Developers should try their best to raise the quality of learning through smartphones and overcome any relevant problems. They are expected to be creative in educational design to make use of such devices and counter their disadvantages, like distraction and the difficulty in entering texts, and find development tools not only for computer and industry specialists, but also for teachers,.

- Sharing: Although some experts believe in the importance of such devices in learning, most parents and teachers do not have the same view. Therefore, standards shall be raised, innovative models promoted, support provided to build the required infrastructure and educational criteria for the industry of such devices developed, like student learning applications. In addition, schools need to adopt tools and work on the students' devices rather than the school computers.

- Preparation: Teachers need to be trained to integrate learning through smartphones. This could be accomplished by training them to make this type of learning within the curricula. That would build the capacity for professionalism; gradually eliminate obstacles in the classroom; innovate behaviour principles to develop admission criteria for students, teachers and parents and integrate the use of these devices in the reading and writing subjects.

In spite of the importance and advantages of learning through smartphones for the educational process in general, according to preliminary findings, the use of this type is still at the beginning. There are challenges which everyone is trying to overcome, so that maximum benefits may be gained. Among the studies addressing the issue is that conducted by Siau, Lim and Shen (2001), which referred to 9 problems, namely: small screens; small keyboards; limited memories; short-term batteries; complicated entry of texts; risky storage and transfer of data; unclear multimedia; unsafe inter-device connections and limited capabilities for graphs.

Shuler (2009) listed a number of challenges. The first has to do with the general disadvantages of these devices, like the long time spent on the screen; difficulty of monitoring students; distractions from learning; health hazards during learning; security concerns for school data; increasing focus on colloquial and abbreviations, which negatively affects students' writing skills, and growing chances for cheating during examinations. The second is related to cultural tendencies. Experts believe that such devices can divert the students' interest from learning, whereas parents and teachers have not yet believed in its role. The third is the lack of a special theory, in spite of the rapid developments of wireless connection technologies, which are hard to follow by teachers and parents. The fourth is about some people's limited physical properties which harm learning through smartphones, as well as the built-in features of such technologies, such as text entry techniques, small screens and short-term batteries. These would hinder perfect learning freedom.

\section{Methodology and Procedures}

\subsection{Sample of the Study}

The sample of the study includes AOU/Jordan students registered in the course of Arabic Teachers for the Primary Stage in Amman Centre. Of the developed questionnaire, 270 copies were distributed, 245 of which were approved. The other 25 were excluded either because a large number of paragraphs were ignored or there was a response set.

Table 1 shows the final distribution of the study according to the study variables.

Table 1. Distribution of the Sample according to Sex, Age and Academic Average

\begin{tabular}{llll}
\hline Variable & & \multicolumn{2}{l}{ Students } \\
\cline { 3 - 4 } & & No. & Percentage \\
\hline Sex & Male & 110 & $44.9 \%$ \\
& Female & 165 & $55.1 \%$ \\
Age & Below 20 & 152 & $62 \%$ \\
& 20+ & 93 & $38 \%$ \\
Academic Average & Below Good & 152 & $62 \%$ \\
& Good+ & 93 & $38 \%$ \\
\hline
\end{tabular}

\subsection{Tool of the Study}

To achieve the objectives of the study, a tool was prepared to measure the use of smartphones by AOU students in learning the Arabic Language. A questionnaire was made by using a watch list through two steps:

I. Identifying the aspects which constitute the components of the questionnaire: That was assisted by previous studies, like Shuler (2009) and Siau, Lim and Shen (2001) 
II. Composing the measurement paragraphs: All the paragraphs which relate to each of the four aspects were collected (Item Pool). Table 2 shows the distribution of measurement paragraphs for each of the four major aspects.

Table 2. Aspects of the Questionnaire on AOU Students' Use of Smartphones in Learning Arabic

\begin{tabular}{ll}
\hline Aspect & No. of Paragraphs \\
\hline Devices used by students in learning Arabic & 11 \\
Smartphone services used by students in learning Arabic & 22 \\
Purposes of the use of smartphones by students in learning Arabic & 16 \\
Challenges to the use of smartphones encountered by students in learning Arabic & 16 \\
Grand Total of Paragraphs & 65 \\
\hline
\end{tabular}

III. Verifying the validity of the questionnaire: In order to check the credibility of the content, mainly from outside, the tool was reviewed by specialists in technology and Arabic Language teaching methods. It was approved by $75 \%$ of the referees, and the proposed modifications were reconciled and made. This way, the logical validity of the questionnaire was secured.

IV. Setting the measurement in its final form: The measurement was made in its final composition in 65 paragraphs, distributed to the four aspects. When it was reviewed again by the referees, the questionnaire was given the final approval as a valid indicator of the problem of the study.

V. Verifying the consistency of the measurement: The indicators on consistency were estimated in two ways:

1. Internal consistency: The questionnaire was applied to a consistency sample through a totally different group of 40 students. The internal consistency coefficients were derived via paragraph statistical significance and Cronbach's Alpha on the overall measurement. It was 0.81 .

2. Test re-application: The questionnaire was applied to the consistency sample a month after the first time, which is sufficient to identify a reliable consistency level. The Pearson correlation coefficients were calculated between both results. The overall consistency coefficient was 0.84 - an acceptable level of the reliability of the questionnaire to achieve the objectives of the study.

\subsection{Procedures of the Study}

The study was conducted through the following steps:

- Choosing the sample individuals

- Building the tool and calculating the validity and consistency psychometric features, by applying the questionnaire on an exploratory sample of 40 students

- Distributing the questionnaire to the individuals to provide answers

- classifying the answers

- Conducting statistical analysis of the data.

\subsection{Statistical Processing}

In addition to frequency and percentage, Chi test was used to check for any statistically significant differences between the learners according to sex (male/female) and age (below/above 20).

\section{Results, Discussion, Recommendations}

\subsection{The Results will be Reviewed and Discussed Altogether as Follows:}

1. What are the types of devices used by AOU students in learning Arabic?

To answer the above question, the number and percentage of users of each device, along with its position, are set in table 3. 
Table 3. Number and Percentage of Device Users and the Position of Each Device

\begin{tabular}{lllll}
\hline No. & Devices & No. of Users & Percentage & Position \\
\hline 1 & Digital sound recorders & 54 & $22 \%$ & 6 \\
2 & Digital game devices & 27 & $11 \%$ & 7 \\
3 & Digital video devices & 100 & $41 \%$ & 4 \\
4 & Digital sound recording devices & 80 & $33 \%$ & 5 \\
5 & GPS & 0 & $0 \%$ & 11 \\
6 & Laptops & 130 & $53 \%$ & 3 \\
7 & Tablets & 5 & $2 \%$ & 9 \\
8 & PDA's & 7 & $3 \%$ & 8 \\
9 & Pocket PC's & 3 & $1 \%$ & 10 \\
10 & Smartphones & 240 & $98 \%$ & 1 \\
11 & Desktops & 238 & $97 \%$ & 2 \\
\hline
\end{tabular}

According to Table 3, learners use all the above tools, except for the GPS, by different percentages. Firstly, 98\% of the learners use smartphones. Such a high rate, even higher than that in Hiasat (2009), is attributed to their wide spread in the society, ease of use, need by all people and numerous applications related to all aspects of life. Secondly, 97\% of learners use desktops for several reasons. Among these are their long-time spread, provision of different software needed by students and suitable for Arabic Language learning environments and capabilities in terms of multimedia like sound, movies, images and writing. Thirdly, learners use laptops by $63 \%$ due to their current wide spread, as indicated by sales statistics of computer companies, advanced mobility, persistent low prices and recharging, which secures their use for 2-4 hours without the need for a power source.

The table also shows that the GPS is the least used service among the respondents, perhaps because it is not very common and it is not needed by learners at this moment. The one before last is the pocket PC by $1 \%$, which could be very helpful in learning Arabic. However, it is not very common in Jordan, and its price does not match the services provided by a desktop or laptop.

2. What are the smartphone services used by AOU students in learning Arabic?

To answer this question, the number of users of each smartphone service in the sample was counted. Then, percentages were set, along with the position of each service, as is displayed in Table 4.

Table 4. Number and Percentage of Service Users and the Position of Each Service

\begin{tabular}{lllll}
\hline No. & Smartphone service & Number & Percentage & Position \\
\hline 1 & Studio & 10 & $4 \%$ & 19 \\
2 & Games & 0 & $0 \%$ & 21 \\
3 & Video capture & 12 & $5 \%$ & 17 \\
4 & Sound recorder & 88 & $36 \%$ & 11 \\
5 & Note taking & 62 & $25 \%$ & 14 \\
6 & Web browser & 189 & $77 \%$ & 4 \\
7 & Video camera & 64 & $26 \%$ & 13 \\
8 & Calendar & 102 & $42 \%$ & 9 \\
9 & Calling & 224 & $91 \%$ & 1 \\
10 & Program downloading & 201 & $82 \%$ & 3 \\
11 & Full screen & 68 & $28 \%$ & 12 \\
12 & Calculator & 4 & $2 \%$ & 20 \\
13 & Bluetooth and infrared connection & 97 & $40 \%$ & 10 \\
14 & SMS & 218 & $89 \%$ & 2 \\
15 & MMS & 132 & $54 \%$ & 7 \\
16 & Alarm & 113 & $46 \%$ & 8 \\
17 & Photo viewer & 0 & $0 \%$ & 21 \\
18 & Photography and filming & 12 & $5 \%$ & 17 \\
19 & Tasks/checklist & 21 & $9 \%$ & 16 \\
20 & GPS & 0 & $0 \%$ & 21 \\
21 & Listening to Arabic radio channels & 166 & $68 \%$ & 5 \\
22 & Browsing e-mail & 162 & $66 \%$ & 6 \\
\hline
\end{tabular}


Table 4 indicates that the students use most of the smartphone services in learning Arabic. Calling comes first by $91 \%$, followed by SMS by $89 \%$. This confirms previous results by Hiasat (2009) on these two, which may be attributed to their ease of use, frequent utilization in everyday life and current low cost. However, some features are never used, such as games, photo viewer and GPS, perhaps because they do not have straightforward applications for the learning of Arabic and some are not widespread.

3. What are the purposes of AOU students when using smartphones in learning Arabic?

To answer this question, the number of students using smartphone services for each purpose in the sample was counted. Then, percentages were set, along with the position of each purpose, as is displayed in Table 5.

Table 5. Number and Percentage of Users' Purposes and the Position of Each Purpose

\begin{tabular}{lllll}
\hline No. & Purpose of Smartphone Use & $\begin{array}{l}\text { No. of } \\
\text { Users }\end{array}$ & $\begin{array}{l}\text { Percentages of } \\
\text { Users }\end{array}$ & Position \\
\hline 1 & Looking for supporting sources in learning Arabic & 39 & $16 \%$ & 12 \\
2 & $\begin{array}{l}\text { Looking for administrative information which } \\
\text { helps in learning Arabic }\end{array}$ & 0 & $0 \%$ & 16 \\
3 & Contacting professors of Arabic & 158 & $64 \%$ & 6 \\
4 & Contacting and sharing with other students in the same course & 195 & $80 \%$ & 3 \\
5 & Looking for programs about learning Arabic on the web & 39 & $16 \%$ & 12 \\
6 & Reading texts from relevant programs & 221 & $90 \%$ & 1 \\
7 & Receiving SMS/MMS about learning Arabic & 59 & $24 \%$ & 11 \\
8 & Answering questions about learning Arabic & 186 & $76 \%$ & 4 \\
9 & Remembering dates related to learning Arabic & 97 & $49 \%$ & 9 \\
10 & Sound recording of data during classes & 179 & $73 \%$ & 5 \\
11 & Setting study schedule and times & 61 & $25 \%$ & 10 \\
12 & Making notes on memorizing and learning Arabic & 29 & $12 \%$ & 15 \\
13 & Taking videos of how certain words or letters are pronounced & 38 & $16 \%$ & 12 \\
14 & Listening to Arabic radios & 124 & $51 \%$ & 8 \\
15 & Listening to language programs from sound & 210 & $86 \%$ & 2 \\
& files on the smartphone & & & 7 \\
16 & Sound recording when reading texts as a revision method & 146 & $60 \%$ & 7 \\
\hline
\end{tabular}

Table 5 shows that students use smartphones in learning Arabic for different purposes. 'Reading texts from relevant programs' comes first by $90 \%$. This could be attributed to the ease of obtaining such applications, low or no cost and frequent need for them in all the stages for learning Arabic. So, they can use them in any time and place, like in means of transportation, in office, at work and between classes, taking into consideration that $98 \%$ of the respondents always hold the smartphones everywhere, as is shown in Table 3. This, again, confirms learning through smartphones.

'Listening to language programs from sound files on the smartphone' comes second by $86 \%$, attributed to the importance of listening to Arabic. The last purpose of 'Looking for administrative information which helps in learning Arabic' is not used by any student, which may be due to the difficulty of having access to administrative websites to learn Arabic through these devices.

4. What are the challenges AOU students think they encounter when using the learning services on their smartphones?

To answer this question, the number of students choosing each challenge was counted. Then, percentages were set, along with the position of each challenge, as is displayed in Table 6. 
Table 6. Number and Percentage of Students Choosing Challenges and the Position of Each Challenge

\begin{tabular}{lllll}
\hline No. & Challenges & $\begin{array}{l}\text { No. of } \\
\text { Students }\end{array}$ & $\begin{array}{l}\text { Percentage of } \\
\text { Students }\end{array}$ & Position \\
\hline 1 & Financial cost of using smartphone services & 221 & $90 \%$ & 3 \\
2 & Lack of specialists in learning through smartphones & 124 & $51 \%$ & 7 \\
3 & Skills required to master using the keyboard & 33 & $14 \%$ & 15 \\
4 & $\begin{array}{l}\text { Dominant educational system which does not help } \\
\text { in employing learning through smartphones in learning Arabic }\end{array}$ & 159 & $65 \%$ & 6 \\
5 & Lack of accuracy and clarity of smartphone images and sounds & 100 & $41 \%$ & 10 \\
6 & Over choice of smartphones & 207 & $84 \%$ & 4 \\
7 & Complicated data transfer, especially with multiplicity of users & 43 & $18 \%$ & 14 \\
8 & Scarcity of programs and applications specialized & 245 & $100 \%$ & 1 \\
& in teaching Arabic through smartphones & & & \\
9 & Slow connection and data transfer & 125 & $51 \%$ & 7 \\
10 & Pressure attributed to continuous learning and training & 20 & $8 \%$ & 16 \\
& anywhere and anytime & & & 12 \\
11 & Rising privacy & 74 & $30 \%$ & 2 \\
12 & Need to train on skills for learning through smartphones & 231 & $94 \%$ & 13 \\
13 & Smartphones' limited capabilities in terms of & 57 & $23 \%$ & \\
& processing and memory & 108 & $44 \%$ & 9 \\
14 & Short battery charging lifetime & 167 & $68 \%$ & 5 \\
15 & Low coverage when there are many users of the wireless network & 75 & $31 \%$ & 11 \\
16 & Distraction of attention & & & \\
\hline
\end{tabular}

Table 6 shows that the respondents believe that all the challenges affect learning through smartphones in learning Arabic. This could be attributed to the fact that it is a relatively new type, of which they feel to encounter many obstacles and of which they are not very aware. 'Scarcity of programs and applications specialized in teaching Arabic through smartphones' comes on the top by $100 \%$. It could be due to the recent emergence of learning through smartphones and, thus, software companies have not been very interested in developing such applications (Shuler, 2009). The 'need to train on skills for learning through smartphones' comes second by $94 \%$, because smartphones have only recently been used in learning, in general, and learning Arabic, in particular. 'Financial cost of using smartphone services' occupies the third place by $90 \%$, due to the fact that many smartphone services are still high, such as sending MMS and internet connection.

The last one is 'pressure attributed to continuous learning and training anywhere and anytime' by $8 \%$. It seems that, since learning Arabic requires constant follow-up, the students are accustomed to such pressure.

5. Are there any statistically significant differences related to the use of smartphones in learning Arabic attributed to age, sex or Academic average?

To answer this question, Chi test was employed with Part Two of the questionnaire on Smartphones by significance level 0.05. Table 7 shows the statistical analysis results between learners based on age, sex and Academic average.

Table 7. Chi Test Results on Differences between Learners in Using Smartphones according to the Variables of Age, Sex and Academic Average

\begin{tabular}{|c|c|c|c|c|c|c|c|c|c|c|}
\hline No. & Device & Age & & & Sex & & & Acade & ic average & \\
\hline & & Chi & p-value & Significance & Chi & p-value & Significance & Chi & $\mathrm{p}$ - value & Significance \\
\hline 1 & Digital sound recorders & 8.11 & 0.001 & Significant & 1.01 & 0.410 & Insignificant & 8.05 & 0.020 & Significant \\
\hline 2 & Digital game devices & 9.56 & 0.354 & Significant & 6.57 & 0.020 & Significant & 3.08 & 0.124 & Insignificant \\
\hline 3 & Digital video cameras & 1.27 & 0.020 & Insignificant & 0.67 & 0.627 & Insignificant & 2.53 & 0.151 & Insignificant \\
\hline 4 & $\begin{array}{l}\text { Digital sound } \\
\text { recording devices }\end{array}$ & 6.51 & 0.208 & Insignificant & 2.02 & 0.181 & Insignificant & 10.14 & 0.001 & Significant \\
\hline 5 & GPS & 1.77 & 0.208 & Significant & 1.10 & 0.380 & Insignificant & 2.00 & 0200 & Insignificant \\
\hline 6 & Laptops & 11.01 & 0.001 & Significant & 4.25 & 0.082 & Insignificant & 11.36 & 0.001 & Significant \\
\hline 7 & Tablets & 0.15 & 1.000 & Insignificant & 1.02 & 0.400 & Insignificant & 3.01 & 0.129 & Insignificant \\
\hline 8 & PDA's & 0.11 & 1.000 & Insignificant & 0.08 & 1.000 & Insignificant & 0.12 & 1.000 & Insignificant \\
\hline 9 & Pocket PC's & 0.10 & 1.000 & Insignificant & 0.14 & 1.000 & Insignificant & 0.08 & 1.000 & Insignificant \\
\hline 10 & Smartphones & 0.01 & 1.000 & Insignificant & 0.21 & 1.000 & Insignificant & 0.10 & 1.000 & Insignificant \\
\hline 11 & Desktops & 0.05 & 1.000 & Insignificant & 0.10 & 1.000 & Insignificant & 0.06 & 1.000 & Insignificant \\
\hline
\end{tabular}


Note: The degree of freedom for all the above tests is 1 .

The results show that there are statistically significant differences between learners when using smartphones in learning Arabic according to the three variables as follows:

a. Age: Four devices show statistically significant differences between students (digital sound recorders, digital game devices, digital sound recording devices and laptops), all in favour of learners below 20. This could have to do with the fact that this category, like most youth, often keeps up with developments of devices and enjoys a high motive to use modern ones, especially those which focus on multimedia services. However, there are no statistically significant differences based on age with regard to other devices. The reason may be that some are used by learners from all age categories, like smartphones and desktops (Wang, Wu and Wang, 2009). On the other hand, other devices, like tablets, pocket PC's and PDA's are not common in the society, as is shown in Table 3 for Question 1.

b. Sex: According to the results, only one device shows individual differences based on the sex variable. It is digital game devices in favour of males. It could be attributed to the fact that females typically prefer holding social relations to using such devices. However, there are no statistically significant differences with regard to other devices. Perhaps they are equally needed by males and females and are widely spread regardless of sex (Wang, Wu and Wang, 2009).

Academic average: Three devices show individual differences between learners (digital sound recorders, digital sound recording devices and laptops) in favour of students with high averages. These learners have trained on using these devices and believe that smartphone services largely facilitate the learning process.

The results of this study are consistent with those of studies as study of Altakhneh (2018) which conducted a study aimed at investigating the attitudes towards mobile learning in open learning systems of teaching mathematics, results of the study showed that the percentages of students' attitudes toward using mobile applications reached $80 \%$.

And study of Cavus and Dogan (2009) which attempted to develop English vocabulary for freshmen at Jordanian universities through SMS. The target students enjoyed learning and acquired more new words than their peers did.

And the study of Shuler (2009) which referred to the following advantages of learning through smartphones.

Considering smartphones usage in teaching and learning process especially in classroom setting is challenging. It offers benefits of rich contents deliverability, knowledge sharing, and dynamic learning activities where students can expect to experience multiple channels of interactions in learning. Nonetheless, in pursuit of this study to uncover the outcome, considering the recommendations and summary of findings, it is encouraged for educators to embrace smartphones in their lesson plans, for example, by taking advantage of it through imposing activities in utilizing their smartphones in the lesson, integrating technology into their methods of teaching. According to the findings from this study, we may expect in the future that the number of smartphone users, especially amongst the youth, is on the rise. Alternatively, by stating rules and regulations in class prior to the start of the lesson may help in minimizing the interferences that they may cause. It has been a challenging process to look for materials in the literature review especially in Brunei's context. However, because of this as well, this would be a good start for other researchers to engage further in this study to uncover more findings with a wider range of sample and targeting the different types of smartphones respondents with more question specifications and anticipated solutions as the outcome.

\section{Recommendations}

Based on the results of the present study, the researcher makes the following recommendations:

- Introducing training courses for teachers on the use of smartphones in learning Arabic

- Finding appropriate solutions to the challenges of the use of smartphone services in learning Arabic

- $\quad$ Conducting studies on other samples to identify the infrastructure necessary to learn and teach Arabic through smartphones.

\section{References}

Abeele, M. M. V. (2016). Mobile lifestyles: Conceptualizing heterogeneity in mobile youth culture. New Media \& Society, 18(6), 908-926. https://doi.org/10.1177/1461444814551349

Almunawar, M. N., Anshari, M., Susanto, H., \& Chen, C. K. (2015).Revealing customer behavior on 
smartphones. International Journal of Asian Business and Information Management, 6(2), 33-49. https://doi.org/10.4018/IJABIM.2015040103

Altakhyneh, B. (2018). Attitudes towards Using Mobile Applications in Teaching Mathematics of the Open Learning system, international Journal of E-Learning \& Distance Education, 33(1), 1-16.

Anshari, M., \& Alas, Y. (2015). Smartphones habits, necessities, and big data challenges. The Journal of High Technology Management Research, 26(2), 177-185. https://doi.org/10.1016/j.hitech.2015.09.005

Anshari, M., Alas, Y., \& Guan, L. S. (2015a). Developing online learning resources: Big data, social networks, and cloud computing to support pervasive knowledge. Education and Information Technologies, 21(6), 1663-1677. https://doi.org/10.1007/s10639-015-9407-3

Anshari, M., Alas, Y., \& Guan, L. S. (2015b). Pervasive Knowledge, Social Networks, and Cloud Computing: E-Learning 2.0. Eurasia Journal of Mathematics, Science \& Technology Education, 11(5), 909-921.

Attewell, J. (2005). Mobile Technologies and Learning. Technology Enhanced Learning Research Center. Published By the Learning and Skills Development Agency, UK.

Au, M., Lam, J., \& Chan, R. (2015). Social media education: Barriers and critical issues. Technology in Education. Transforming Educational Practices with Technology (pp. 199-205).Springer Berlin Heidelberg. https://doi.org/10.1007/978-3-662-46158-7_20

Cavus, N., \& Dogan, I. (2009). M-Learning: An experiment in using SMS to support learning new English language words. British Journal of Educational Technology, 40(1), 78-91. https://doi.org/10.1111/j.1467-8535.2007.00801.x

Corbett, S. (2008). Can the cell phone help and global poverty?. The New York Times. April 13, Retrieved from http://www.nytimes.com/2008/04/13/magazine/13 anthropologyt.html

Course, S. (2011). Digital Dependence of Today's College Students Revealed in New Study from Course smart. Retrieved from http://www.reuters.com/article/2011/06/01/idUS141122 01-Jun-2011

Davies, Z. (2015). Definition of: Smartphone. USA: PCMag Digital Group. Retrieved from http://www.pcmag.com/encyclopedia/term/51537/smartphone

Demb, A., Erikson, D., \& Hawkins-Wilding, S. (2004). The notebook alternative: Student's reactions and strategic implications. Computers \& Education, 43, 383-401. https://doi.org/10.1016/j.compedu.2003.08.008

Evans, M. (2009). Mobility, games, and education. Handbook of Research on Effective Electronic Gaming in Education (pp. 96-110). New York: NIG Publishing. https://doi.org/10.4018/978-1-59904-808-6.ch006

García-Ormaechea, I., González, I., Duplá, M., Andres, E., \&Pueyo, V. (2014). Validation of the preverbal visual assessment (PreViAs) questionnaire. Early human development, 90(10), 635-638. https://doi.org/10.1016/j.earlhumdev.2014.08.002

Gerlich, R. N., Browning, L., \& Westermann, L. (2010). The social media affinity scale: implications for education. Contemporary Issues in Education Research, 3(11), 35-42. https://doi.org/10.19030/cier.v3i11.245

Goh, K. (2006). Getting Ready for Mobile Learning-Adaptation Perspective. JI of Educational Multimedia and Hypermadia, 15(2), 175-198.

Imelda, I., Bamban, Y., \& Utari, P. (2019). Effect of Process Writing Approach Combined with Video-Based Mobile Learning on Indonesian EFL Learners' Writing Skill across Creativity Levels. International Journal of Instruction, 12(3), 325-340. https://doi.org/10.29333/iji.2019.12320a

Katz, N. (2012). Teens and Smartphones: The Good The Bad and The Ugly. Retrieved from http://www.socialmoms.com/tech/teens-and-smartphones-the-good-the-bad-and-the-ugly

Mohamed, A. (2009). Mobile Learning Transforming the Delivery of Education and Training. Issues in Distance Education Series, Published by AU Press, Athabasca University.

Nakamura, H., Hanamitsu, N., \& Minamizawa, K. (2015). A (touch) ment: a smartphone extension for instantly sharing visual and tactile experience. In: Proceedings of the 6th Augmented Human International Conference (pp. 223-224). ACM. https://doi.org/10.1145/2735711.2735782

Prensky, M. (2005). In What Can You Learn from a Cell Phone? Almost Anything. Journal of online education, $5(1), 34-41$. 
Quinn, C. (2000). M Learning: mobile, wireless, in your-pocket learning. Line Zine. Retrieved from www.linezine.com/2.1/features/cqmmwipy.htm

Sharples, M. (2000). The design of personal mobile technologies for lifelong learning. Computers and Education, 34(2), 177-193. https://doi.org/10.1016/S0360-1315(99)00044-5

Shuler, C. (2009). Pockets of Potential: Using Mobile Technologies to Promote Children's Learning. The Joan Ganz Coony Center at Sesame workshop. New York.

Siau, K., Lim, E.-P., \& Shen, Z. (2001). Mobile commerce: promises, challenges, and research agenda. Journal of Database Management, 12(3), 4-13. https://doi.org/10.4018/jdm.2001070101

Stephens, B. R. (2005). Notebook in psychology: conducting flexible In-class research and writing laboratories. New Directions for Teaching and Learning, 101, 15-26. https://doi.org/10.1002/tl.182

Yu-Shun, W., Ming-Cheng, W., \& Hisu-Yuan, W. (2009). Investigating the determinants and age and gender differences in the acceptance of mobile learning. British Journal of Educational Technology, 40(1), 92-118. https://doi.org/10.1111/j.1467-8535.2007.00809.x

\section{Copyrights}

Copyright for this article is retained by the author(s), with first publication rights granted to the journal.

This is an open-access article distributed under the terms and conditions of the Creative Commons Attribution license (http://creativecommons.org/licenses/by/4.0/). 